\title{
A Doppler ultrasonographic study of cyclic changes of ovarian perfusion in the Beagle bitch
}

\author{
K. Köster ${ }^{1}$, C. Poulsen Nautrup ${ }^{2}$ and A-R. Günzel-Apel1* \\ ${ }^{1}$ Institute for Reproductive Medicine, School of Veterinary Medicine Hannover, Bünteweg \\ 15, D-30559 Hannover, Germany; and ${ }^{2}$ Institute for Veterinary Anatomy I, Veterinary \\ Faculty, University of Munich, Germany
}

Changes in intraovarian arterial blood flow were monitored by means of colour-coded and pulsed Doppler ultrasonography in Beagle bitches during the normal oestrous cycle $(n=11)$ and pregnancy $(n=3)$, and at PGF $2 \alpha^{-}$ induced luteolysis $(n=4)$. The ultrasonographic findings were related to the reproductive stage of the bitch, as determined by vaginoscopical and cytological criteria, and by the concentrations of oestradiol, $\mathrm{LH}$ and progesterone in peripheral blood plasma. Colour-coded Doppler ultrasonography was used to visualize and estimate intraovarian vascularization, and pulsed Doppler ultrasonography was used to measure the arterial blood flow. The systolic and diastolic peak velocities, the end-diastolic velocity, and the pulsatility index and resistance index were calculated for quantitative analysis of the Doppler waveforms. Intraovarian perfusion increased gradually during pro-oestrus. A marked enhancement of intraovarian colouring and blood flow velocities, and a decline in the indices for pulsatility and resistance were observed in the preovulatory period. Maximum perfusion was observed at ovulation and during the early luteal phase. Significant differences $(P<0.05)$ were detected for the values of all calculated Doppler parameters 2 days before and 2 days after ovulation. Intraovarian blood flow decreased gradually in accordance with luteal regression. Treatment with $\mathbf{P G F}_{2 \alpha}$ caused a distinct decline in luteal activity and a concomitant reduction in intraovarian perfusion. The values of blood flow parameters found during the luteal phase of pregnant bitches were comparable to those of the normocyclic bitches. Doppler ultrasonography of the intraovarian arteries in bitches provides complementary information about cyclic changes of ovarian function.

\section{Introduction}

The ovarian cycle of bitches is usually monitored by the assessment of characteristic changes of the vaginal mucosa and vaginal epithelium, and the analysis of endocrine parameters (Concannon et al., 1975; Lindsay, 1983; Jeffcoate and Lindsay, 1989; Waberski and Günzel-Apel, 1990). In addition, two-dimensional ultrasonography is used for direct imaging of the cyclic changes of ovarian structures (Boyd et al., 1993; England and Yeager, 1993; Hayer et al., 1993; Günzel-Apel and Dieterich, 1996). However, conventional B-mode ultrasonography does not provide information about the functional state and activity of ovarian tissues. The mature female gonad is constantly subjected to cyclic changes. The concomitantly changing metabolic conditions are crucially dependent on the adaptation of local blood supply. Thus, at the stage of maximum endocrine activity, the ovary is the most perfused organ of the body (Ellinwood et al., 1978).

According to histological studies, cyclic changes in ovarian vascularization occur in many mammalian species

*Correspondence

Email: Anne-Rose.Guenzel-Apel@tiho-hannover.de and reflect the functional stages of the female gonads (Basset, 1943; Andersen and Simpson, 1973; Ellinwood et al., 1978; Peters and McNatty, 1980). Investigations on the dynamics of ovarian blood flow have been carried out in different mammalian species using invasive techniques such as radioactive microspheres (sheep: Niswender et al., 1975; rabbit: Janson, 1975; Wiltbank et al., 1990), implantation of Doppler transducers (sheep: Brown et al., 1980) and electromagnetic flowmeters (cattle: Ford and Chenault, 1981). However, these experimental methods are not suitable for diagnostic application in animals or humans.

The technical improvement of Doppler ultrasonography permits the direct, non-invasive and harmless estimation of the peripheral blood circulation throughout the oestrous cycle.

Despite numerous reports on the use of Doppler ultrasonography in the diagnosis of ovarian function and dysfunction in humans (Taylor and Burns, 1985; Scholtes et al., 1989; Hata et al., 1990; Collins et al., 1991; Fleischer, 1991; Campbell et al., 1993; Goswamy, 1993; Kupesic and Kurjak, 1993; Sladevicius et al., 1993; Locci et al., 1994; Bourne et al., 1995; Sohn, 1995; Tinkanen et al., 1995; Tan et al., 1996; Zaidi et al., 1996; Kurjak and Kupesic, 1997; Brännström et al., 1998), comparable data 
from animal reproduction are scarce (Baumgartner et al., 1998). For quantitative evaluation of the detected Doppler frequency spectrum, the systolic peak velocity (SPV) and the pulsatility index $(\mathrm{PI})$ or the resistance index (RI) are preferably used. Detection of venous ovarian blood flow does not yield any valuable information (Kurjak and Kupesic, 1997). The results of these studies, in which alterations of ovarian perfusion is in accordance with ovarian endocrine function, correspond almost entirely. Deviations from normal cyclic findings were observed in human pregnancy (Zalud and Kurjak, 1990; Goswamy, 1993), senescence (Locci et al., 1994; Kurjak and Kupesic, 1995), pathological ovarian function (Bourne et al., 1991; Kurjak and Kupesic-Urec, 1991; Kupesic and Kurjak, 1993; Schurz et al., 1993; Weiner et al., 1993; Strigini et al., 1995; Kurjak and Kupesic, 1997) and in the case of ovarian neoplasia (Bourne et al., 1989; Fleischer, 1991; Sohn et al., 1993; Sohn, 1995; Tekay and Jouppila, 1995).

The aim of the present study was to acquire basal values for the intraovarian blood flow in the bitch throughout the normal oestrous cycle and pregnancy, and at $\mathrm{PGF}_{2 \alpha}$-induced early luteolysis.

\section{Materials and Methods}

Fifteen healthy Beagle bitches 2-10 years of age, from the Institute for Reproductive Medicine, School of Veterinary Medicine, Hannover, were examined. Animal housing, care and experimentation complied with the animal welfare regulations of Germany.

Eleven physiological oestrous cycles were used for evaluation of basal Doppler ultrasonographic data. Ultrasound examinations were performed each day during pro-oestrus and oestrus until the onset of cytological metoestrus as defined by Holst and Phemister (1974), and were continued at 10 day intervals from day 10 to day 70 after ovulation. Three of these bitches became pregnant at the next oestrus and were again subjected to the same examination schedule. In four inseminated bitches, which were also involved in a study on prevention of implantation, luteal function was inhibited by s.c. injections of $50-100 \mu \mathrm{g} \mathrm{PGF}_{2 \alpha} \mathrm{kg}^{-1}$ (Dinolytic ${ }^{\circledR}$, Upjohn, Erlangen) every $8 \mathrm{~h}$ from day 12 after ovulation and for the subsequent 7 days (Salpigtidou, 1998). In this group, one additional ultrasound examination was performed at day 15 after ovulation.

During pro-oestrus, follicular activity was monitored each day by examining vaginal mucosa and vaginal cytology (Jeffcoate and Lindsay, 1989), and by using Bmode ultrasonography as described by Günzel-Apel and Dieterich (1996). For determination of ovulation, complementary semi-quantitative analysis of progesterone concentrations in peripheral plasma was performed at 2 day intervals starting at late pro-oestrus, to detect the preovulatory progesterone increase, using the Canine ovulation timing kit (Biometallics, Princeton, NY) (Waberski and Günzel-Apel, 1990; Günzel-Apel 1997). Additional blood samples were collected in accordance with the ultrasound examinations. The samples of blood plasma were stored at $-18^{\circ} \mathrm{C}$ until hormone analysis. Concentrations of oestradiol, progesterone and $\mathrm{LH}$ were measured by radioimmunoassay as described by Höveler (1991) for oestradiol, by Sieme (1989) for progesterone and by Günzel-Apel et al. (1990) for canine LH.

For ultrasonographic examinations, the ultrasound system LOGIQ 500 (General Electrics, Medizinische Geräte, Solingen) equipped with a 7.5 MHz-linear scanner for B-mode as well as for colour-coded and pulsed Doppler measurements was used. Ultrasonography was performed from the left and right shaved flank as described by Hayer et al. (1993). The ovaries were identified behind the caudal pole of the ipsilateral kidney.

Intraovarian vascularization was visualized using colourcoded Doppler ultrasonography (Duplex-mode). The size of the colour-coded area was usually limited to the maximum extent of the ovary. In the sectional plane of maximum intraovarian colouring the optimum Nyquist limit, and the filter and gain were estimated at each examination.

For quantitative analysis, intraovarian vessels were colour-coded and the Doppler spectrum was calculated simultaneously within a pulsed-wave range gate (Triplexmode). Only arterial waveforms with maximum Doppler shift, in which several successive heart cycles could be precisely imaged, were included in the study. The sample volume was adjusted to surround the entire lumen of a vessel. In consideration of the breathing-related movements of the abdomen, the sample volume was aligned at the expiratory position of the colour-pixel. The insonation angle between Doppler stream and course of the vascular segment was corrected manually. Angles of $>60^{\circ}$ were excluded from further quantification.

Each examination included the detection of flow velocity waveforms of good quality in at least three heart cycles within three different intraovarian locations. The systolic and diastolic peak velocity (SPV and DPV) and the enddiastolic velocity (EDV) of the outlined waveform were determined. Impedance of blood flow was estimated by the peak-to-peak pulsatility index (PPI = SPV - EDV/TAMAX (TAMAX = time averaged maximum velocity)) and the resistance index $(\mathrm{RI}=\mathrm{SPV}-\mathrm{EDV} / \mathrm{SPV})$.

\section{Statistical analysis}

Statistical analysis was performed by means of the computer program SAS ${ }^{\circledR}$ (Statistical Analysis System). All values of Doppler parameters and hormone concentrations were mean \pm SD. The Student's t test was used to compare Doppler parameters of representative days of the oestrous cycle (days from ovulation (day 0 ): $-6,-4,-3,-2,-1,0,1$, 2 , 5, 10, 15, 20, 30, 40, 50, 60 and 70). For presentation of the results, the data in Figs $1-3$ are limited to 3 representative days of the follicular phase until ovulation (days $-6,-2$ and 0 ) and to 6 days of the luteal phase (days 2, 10, 20, 30, 50 and 70 after ovulation). 

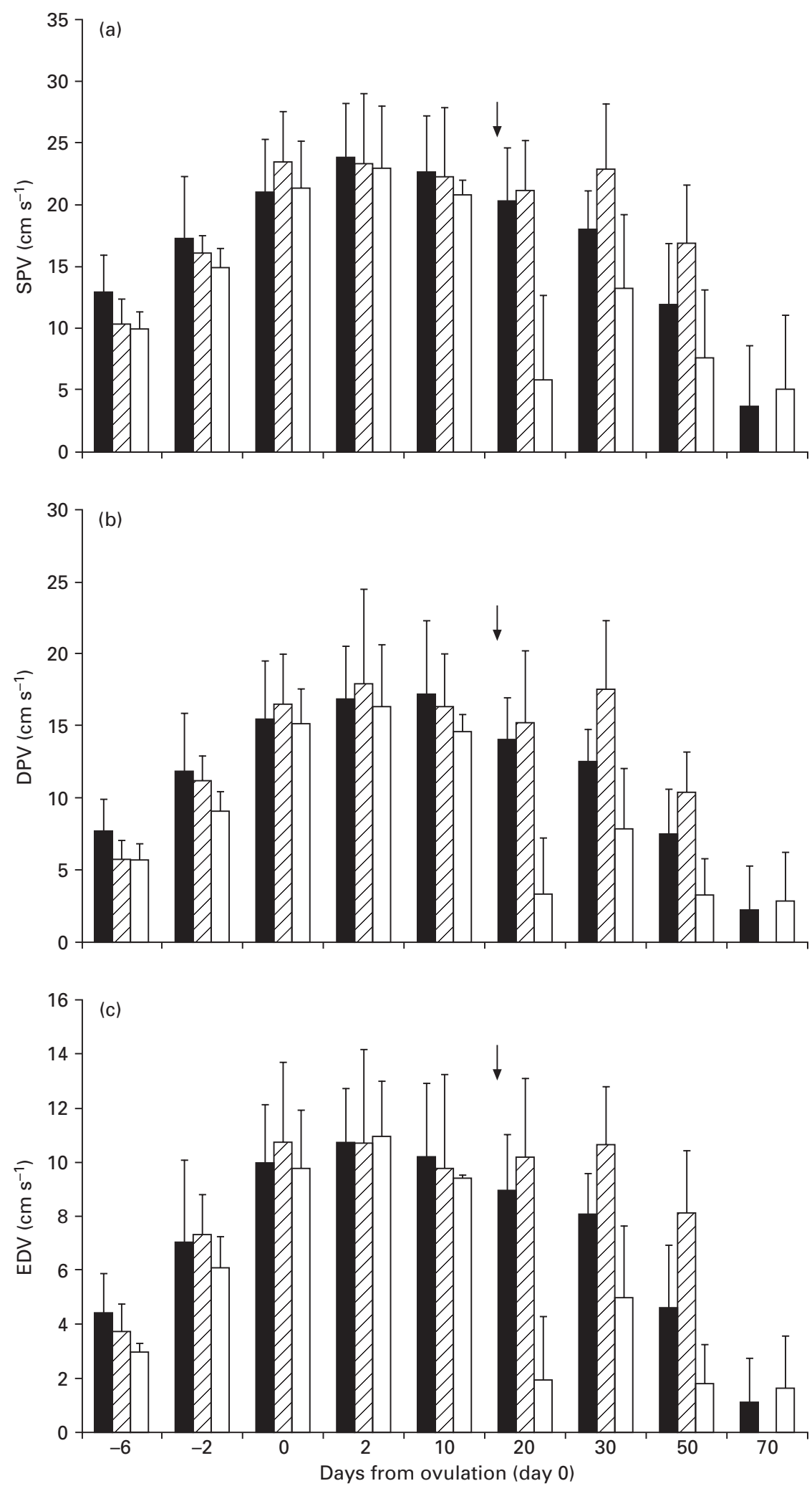

Fig. 1. (a) Systolic peak velocity (SPV), (b) diastolic peak velocity (DPV) and (c) enddiastolic velocity (EDV) of blood flow in the left intraovarian arteries in Beagle bitches

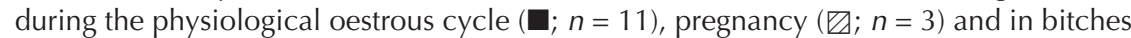
treated with $\mathrm{PGF}_{2 \alpha}$ from day 12 to day 18 after ovulation $(\square ;$ arrow; $n=4)$. Values obtained 2 days before ovulation (day -2) and 2 days after ovulation (day 2) are significantly different $(P<0.05)$. 

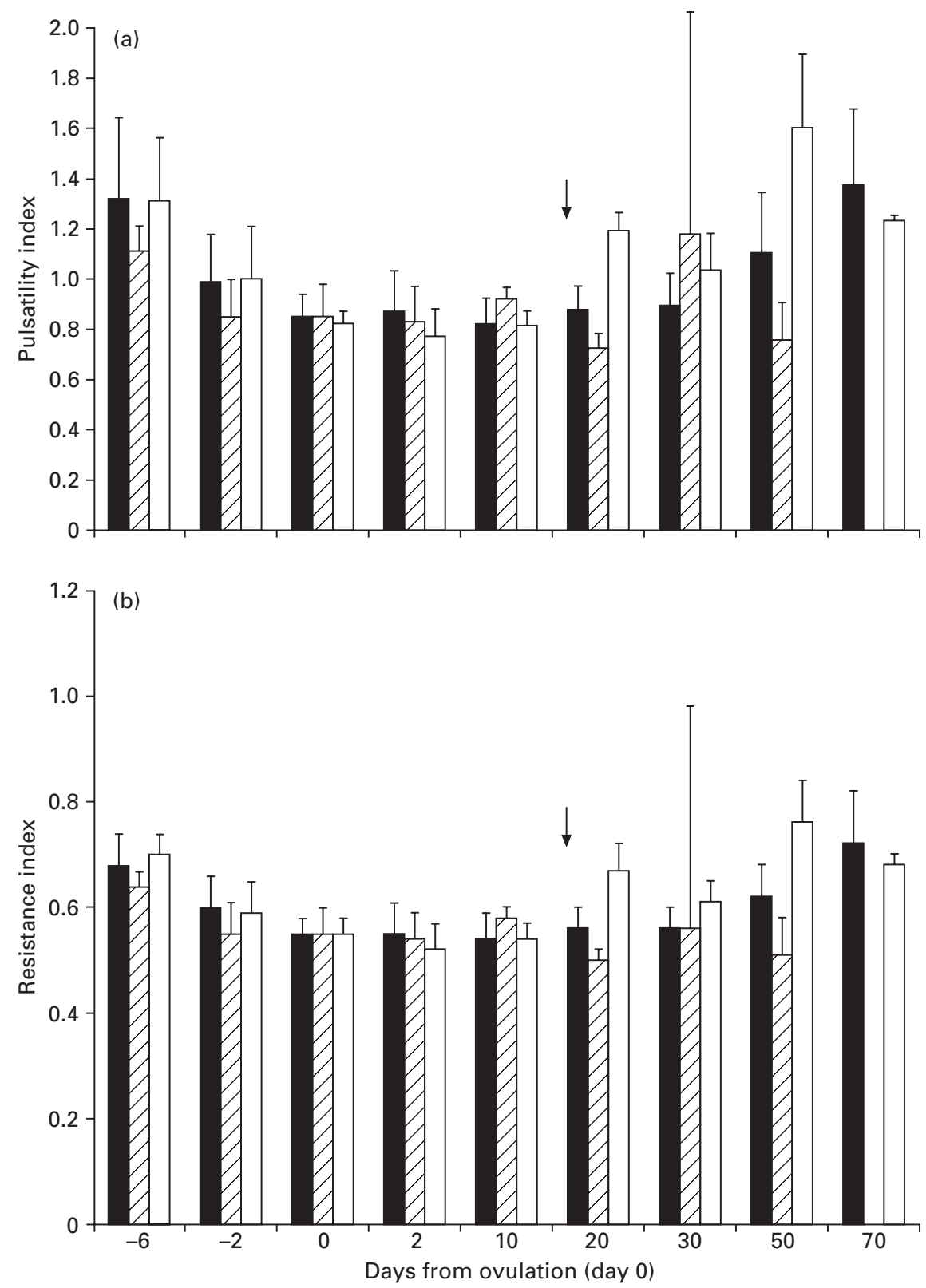

Fig. 2. (a) Peak-to-peak pulsatility index and (b) resistance index of blood flow in the left intraovarian arteries in Beagle bitches during the physiological oestrous cycle $(\mathbf{\square} ; n=11)$,

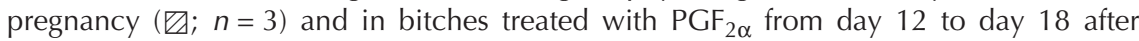
ovulation ( $\square$; arrow; $n=4$ ). Values obtained 2 days before ovulation (day -2$)$ and 2 days after ovulation (day 2 ) are significantly different $(P<0.05)$.

Values obtained for contralateral ovaries were analysed for significant differences at days $-6,0,5,30$ and 60 . $P$ values of $<0.05$ were considered significant.

\section{Results}

Intraovarian perfusion of the left and right ovary

Comparison of the blood flow in the left and right ovarian artery revealed similar tendencies in both sides during the oestrous cycle (Table 1). Significant differences between ovaries were obtained for EDV and PPI at day -6 , for PPI at day 0 , for PPI and for RI at day 5 after ovulation, and for EDV and DPV at day 30, indicating an uneven developmental stage of individual ovaries in the same bitch. Thus changes in the blood flow of intraovarian arteries were demonstrated only for the left gonad. 




Fig. 3. Progesterone concentrations $\left(\mathrm{ng} \mathrm{ml}^{-1}\right)$ in Beagle bitches during the physiological oestrous cycle $(\mathbf{\square} ; n=11)$, pregnancy $(\square ; n=3)$ and in bitches treated with $\mathrm{PGF}_{2 \alpha}$ from day 12 to day 18 after ovulation ( $\square$; arrow; $n=4$ ).

Table 1. Measurements (mean \pm SD) of the left and right intraovarian arteries in Beagle bitches at representative days of the oestrous cycle $(n=11)$ using Doppler ultrasonography

\begin{tabular}{|c|c|c|c|c|c|c|}
\hline $\begin{array}{l}\text { Day from } \\
\text { ovulation } \\
(\text { day } 0)\end{array}$ & Ovary & $\begin{array}{c}\text { Systolic peak } \\
\text { velocity } \\
\left(\mathrm{cm} \mathrm{s}^{-1}\right)\end{array}$ & $\begin{array}{c}\text { Diastolic peak } \\
\text { velocity } \\
\left(\mathrm{cm} \mathrm{s}^{-1}\right)\end{array}$ & $\begin{array}{c}\text { End-diastolic } \\
\text { velocity } \\
\left(\mathrm{cm} \mathrm{s}^{-1}\right)\end{array}$ & $\begin{array}{l}\text { Peak-to-peak } \\
\text { pulsatility index }\end{array}$ & Resistance index \\
\hline \multirow[t]{2}{*}{-6} & L & $13.82 \pm 3.00$ & $8.08 \pm 2.19$ & $3.86 \pm 1.16$ & $1.44 \pm 0.27$ & $0.68 \pm 0.06$ \\
\hline & $\mathrm{R}$ & $12.34 \pm 3.16$ & $7.00 \pm 2.12$ & $3.30 \pm 1.00$ & $1.48 \pm 0.35$ & $0.73 \pm 0.07$ \\
\hline \multirow[t]{2}{*}{-2} & $\mathrm{~L}$ & $17.32 \pm 5.01$ & $11.84 \pm 4.07$ & $7.03 \pm 3.07$ & $0.99 \pm 0.19$ & $0.60 \pm 0.06$ \\
\hline & $\mathrm{R}$ & $15.00 \pm 1.68$ & $10.33 \pm 1.82$ & $5.82 \pm 1.62$ & $1.16 \pm 0.35$ & $0.64 \pm 0.08$ \\
\hline \multirow[t]{2}{*}{0} & $\mathrm{~L}$ & $21.09 \pm 4.25$ & $15.50 \pm 4.07$ & $9.97 \pm 2.19$ & $0.85 \pm 0.09$ & $0.55 \pm 0.03$ \\
\hline & $\mathrm{R}$ & $23.14 \pm 6.30$ & $15.87 \pm 5.94$ & $10.08 \pm 3.68$ & $0.95 \pm 0.15$ & $0.57 \pm 0.05$ \\
\hline \multirow[t]{2}{*}{2} & $\mathrm{~L}$ & $23.89 \pm 4.30$ & $16.93 \pm 3.74$ & $10.77 \pm 1.98$ & $0.87 \pm 0.16$ & $0.55 \pm 0.06$ \\
\hline & $\mathrm{R}$ & $21.82 \pm 3.80$ & $15.56 \pm 3.81$ & $9.09 \pm 2.12$ & $0.97 \pm 0.19$ & $0.58 \pm 0.06$ \\
\hline \multirow[t]{2}{*}{5} & $\mathrm{~L}$ & $22.03 \pm 5.05$ & $15.26 \pm 3.57$ & $9.80 \pm 2.42$ & $0.85 \pm 0.12$ & $0.55 \pm 0.05$ \\
\hline & $\mathrm{R}$ & $21.65 \pm 6.49$ & $15.06 \pm 4.63$ & $8.36 \pm 3.49$ & $1.05 \pm 0.19$ & $0.62 \pm 0.06$ \\
\hline \multirow[t]{2}{*}{10} & $\mathrm{~L}$ & $22.70 \pm 4.49$ & $17.29 \pm 4.53$ & $10.21 \pm 2.72$ & $0.82 \pm 0.11$ & $0.54 \pm 0.05$ \\
\hline & $\mathrm{R}$ & $22.80 \pm 6.46$ & $15.05 \pm 4.69$ & $9.39 \pm 3.77$ & $1.01 \pm 0.32$ & $0.59 \pm 0.07$ \\
\hline \multirow[t]{2}{*}{30} & $\mathrm{~L}$ & $18.15 \pm 3.08$ & $12.62 \pm 2.21$ & $8.09 \pm 1.49$ & $0.89 \pm 0.13$ & $0.56 \pm 0.04$ \\
\hline & $\mathrm{R}$ & $16.19 \pm 5.09$ & $10.59 \pm 3.13$ & $6.19 \pm 2.23$ & $1.05 \pm 0.22$ & $0.61 \pm 0.07$ \\
\hline \multirow[t]{2}{*}{50} & $\mathrm{~L}$ & $11.99 \pm 4.93$ & $7.56 \pm 3.15$ & $4.63 \pm 2.30$ & $1.10 \pm 0.24$ & $0.62 \pm 0.06$ \\
\hline & $\mathrm{R}$ & $10.49 \pm 4.02$ & $5.99 \pm 2.49$ & $3.28 \pm 1.47$ & $1.40 \pm 0.40$ & $0.69 \pm 0.06$ \\
\hline \multirow[t]{2}{*}{70} & L & $3.80 \pm 4.88$ & $2.31 \pm 3.03$ & $1.14 \pm 1.63$ & $1.37 \pm 0.30$ & $0.72 \pm 0.10$ \\
\hline & $\mathrm{R}$ & $2.70 \pm 4.67$ & $1.69 \pm 2.91$ & $0.87 \pm 1.63$ & $1.27 \pm 0.46$ & $0.68 \pm 0.09$ \\
\hline
\end{tabular}

L: left ovary; R: right ovary.

Physiological follicular phase, ovulation and early luteal phase (from day 6 before ovulation to day 10 after ovulation)

In the first few days of pro-oestrus, colour-coded blood flow was scarcely detectable in most ovaries, even when the Nyquist limit was at the lowest setting. In the later stages of the follicular phase, the number, extent and intensity of intraovarian colour pixels increased gradually and Doppler parameters could be calculated in all ovaries from day 6 before ovulation (day -6$)$. Flow velocity waveforms were characterized by a sharp systolic increase and decrease followed by a flat diastolic peak and a low end-diastolic velocity. During the follicular phase, the flow velocities 
increased gradually, but PPI and RI remained constant or were reduced very slightly.

In the preovulatory period, a rapid increase in intraovarian colouring occurred. This event coincided with the $\mathrm{LH}$ peak in 17 of 36 ovaries $(47.2 \%)$, preceded the $\mathrm{LH}$ peak by 1 day in six ovaries $(16.7 \%)$ and occurred the day after the LH peak in ten gonads $(27.7 \%)$. In two ovaries $(5.5 \%)$, the increase of intraovarian colouring was observed 2 days after the LH surge and in one ovary $(2.8 \%)$ the increase occurred 3 days thereafter. The quantitative evaluation of blood flow showed a marked enhancement of SPV, DPV and EDV, but a decrease in PPI and RI (Table 1; Figs 1 and 2). High absolute velocities, an indistinct prediastolic notch and a smooth transition to the end-diastolic phase characterized the patterns of blood flow. These marked alterations occurred in all bitches before ovulation, but showed individual variation.

At 2 days before ovulation, the mean progesterone concentrations showed a marked increase from basal amounts, indicating preovulatory follicle luteinization induced by LH (Fig. 3). Progesterone concentrations continued to increase at ovulation and during luteal development at day 2 and at day 10 after ovulation (Fig. 3).

Concomitantly, intraovarian colouring and the maximum Doppler frequency reached highest values at the day of ovulation and during the early luteal phase (at day 2 and day 10 after ovulation), thus facilitating the alignment of the sample volume in the colour-coded pixels and the registration of the Doppler shifts.

The Doppler parameters changed less rapidly after ovulation. Mean values of SPV, DPV and most markedly EDV were highest, whereas PPI and RI reached lowest values during the period from ovulation to day 10 thereafter (Table 1; Figs 1 and 2). At 2 days after ovulation, SPV, DPV and EDV were significantly higher, and PPI and RI were significantly lower than at day 2 before ovulation. The patterns of intraovarian blood flow of normal cyclic bitches were similar to the pattern in the follicular and early luteal phase (day -6 to day 10) of the pregnant bitches and the $\mathrm{PGF}_{2 \alpha}$-treated Beagles (Figs 1 and 2).

\section{Physiological luteal phase (from day 10 to day 70 after ovulation)}

During the luteal phase of the normal oestrous cycle, a gradual individually varying reduction of intraovarian colouring was observed. The blood flow velocities continued to decrease simultaneously from day 30 after ovulation. The PPI and RI started to increase from day 40 after ovulation (PPI $1.02 \pm 0.11 ; R I 0.61 \pm 0.03$ ). On day 50, all parameters measured by Doppler ultrasonography were similar to those found in early pro-oestrus (day -6) (Figs 1 and 2). No blood flow was detected in $63.6 \%$ (14 of 22) of the normocyclic ovaries at 70 days after ovulation even at the lowest Nyquist limit. The concomitant gradual decrease of progesterone concentrations indicated physiological luteal regression from day 30 to day 70 (Fig. 3).

\section{Luteal phase during pregnancy}

Throughout the luteal phase of pregnant bitches, intraovarian blood flow velocities and vascular impedance, and progesterone concentrations were similar to those observed in the physiological oestrous cycle (Figs 1-3). However, an individual variability of the parameters measured by Doppler ultrasonography was observed in the prepartum period (day 60 after ovulation). In one bitch, no intraovarian vascularization could be detected due to prepartum luteolysis, as shown by a progesterone concentration of $5.0 \mathrm{ng} \mathrm{ml}^{-1}$, and by the occurrence of parturition within a few hours after the ultrasound examination. In the other two pregnant bitches, higher flow velocities and lower indices were recorded (SPV 17.03 and 17.23; DPV 8.31 and 9.01; EDV 6.11 and 6.23; PPI 1.17 and 1.09; RI 0.63 and 0.60). One of these bitches whelped 4 days later and a Caesarean section was performed on the other bitch at day 65 after ovulation.

\section{Luteal phase influenced by $P G F_{2 \alpha}$}

At day 15 after ovulation, which was day 4 of $\mathrm{PGF}_{2 \alpha}$ treatment, the mean progesterone concentration had decreased sharply from $18.5 \pm 3.5 \mathrm{ng} \mathrm{ml}^{-1}$ (day 10) to $2.9 \pm 3.4 \mathrm{ng} \mathrm{ml}^{-1}$. Concomitantly, a marked decrease in intraovarian colouring was observed in all four bitches. In two bitches, arterial blood flow was even below the lowest measurable Doppler frequency. The mean values of the measured blood flow velocities were $4.99 \pm 5.77$ for SPV, $2.88 \pm 3.33$ for DPV and $2.01 \pm 2.38$ for EDV (in both cases $n=4$ ), which indicate a sharp decline in intraovarian perfusion from day 10 to day 15 after ovulation. The values for PPI $(1.04 \pm 0.33)$ and RI $(0.59 \pm 0.10)$ (in both cases $n=2$ ) were increased accordingly. Similar values for the blood flow parameters were still observed at day 20 after ovulation (Figs 1 and 2). At the same time, that is 2 days after cessation of $\mathrm{PGF}_{2 \alpha}$ treatment, progesterone values showed a slight increase for the first time, which persisted until day 30 , indicating functional recovery of the corpora lutea (Fig. $3)$. This increase was accompanied by another increase in intraovarian colouring, reaching values similar to those before the onset of $\mathrm{PGF}_{2 \alpha}$ treatment in three of four bitches (SPV 17.1-21.3; DPV 6.84-13.77; EDV 4.47-8.73) and by a moderate decline of Doppler parameters (PPI 0.91-1.18, RI 0.58-0.65). In one bitch, ovarian perfusion remained below limits of detection. The decreased progesterone concentrations at day 50 and day 70 after ovulation were similar to those found in bitches at physiological luteal regression (Fig. 3). SPV, DPV and EDV decreased simultaneously (Fig. 1), whereas PPI and RI increased to initial values (Fig. 2) similar to the patterns found at physiological luteal regression. At day 70 after ovulation, colour pixels were detected in only two of four bitches in this group.

\section{Discussion}

The results of the present study demonstrate marked alterations in intraovarian blood flow in the course of the 
canine oestrous cycle. It has been suggested that haemodynamic changes are essential for modelling and for the function of reproductive tissues (Ellinwood et al., 1978; Reynolds et al., 1992). Other studies that used invasive techniques (Janson, 1975; Niswender et al., 1975; Brown et al., 1980; Wiltbank et al., 1990), as well as histological investigations in different mammalian species (Basset, 1943; Andersen and Simpson, 1973; Ellinwood et al., 1978; Peters and McNatty, 1980) consistently describe a cyclic increase and reduction of ovarian perfusion. A moderate increase in ovarian vascularization during the follicular phase is attributed to the influence of various angiogenetic growth factors, which are stimulated by gonadotrophins and produced by the proliferating cells of the follicular wall (Klagsbrun and D'Amore, 1991; Reynolds et al., 1992).

In the preovulatory period, a marked increase of intraovarian colouring was observed in association with the LH surge, and coincided with a marked increase in the SPV and DPV, and the EDV. The higher increase of DPV and EDV in relation to SPV caused a concomitant decrease in PI and RI. A reduction of $\mathrm{RI}$ due to the increase in EDV indicates an increase in perfusion (Deeg et al., 1990). Therefore, the blood flow pattern in intraovarian arteries is the result of an enhanced blood flow in the small parenchymal vessels and from a decrease in the resistance of the vascular wall. The LH surge induces preovulatory luteinization of the follicular wall and initial progesterone production (Concannon et al., 1977, 1989; Wildt et al., 1979; Concannon, 1993), which was confirmed in the present study by the preovulatory progesterone increase at day -2 . The increasing metabolic activity requires adequate blood supply of the steroid hormone synthesizing lutein cells. The stimulating effect of $\mathrm{LH}$ on tissue perfusion has been shown in many mammalian species including humans (Wurtman, 1964; Piascek and Huth, 1971; Janson, 1975; Niswender et al., 1975; Lee and Novy, 1978; Weiner et al., 1993). In addition to the stimulation of angiogenesis (Findlay, 1986), LH induces a marked dilation of the arteries and arterioles present in the proliferating follicular wall, which is mediated by vasoactive substances such as eicosanoids, kinins and prostaglandins. As the newly formed capillaries are sinusoidal vessels without smooth muscle they hardly impede vascular perfusion (Cavender and Murdoch, 1988; Wiltbank et al., 1990). The rapid increase in blood flow enhances the supply of nutrients and oxygen to the preovulatory follicle; these nutrients are essential for the ovulatory process and the onset of progesterone production, respectively (Niswender et al., 1975; Espey, 1976; Ellinwood et al., 1978).

Ovulation and the early luteal phase in bitches are characterized by high blood flow velocities and low PPI and RI. Maximum perfusion has been assumed to reflect the period of highest progesterone production (Janson, 1975; Niswender et al., 1975; Brown et al., 1980; Ellinwood et al., 1978; Wiltbank et al., 1990). However, luteal regression is accompanied by a gradual decline in ovarian blood supply. Accordingly, data obtained in normocyclic and pregnant bitches indicate a causal correlation between ovarian blood supply and progesterone production. In addition, the $\mathrm{PGF}_{2 \alpha}$-induced inhibition of luteal activity, as demonstrated by a reduction of progesterone synthesis (Salpigtidou, 1998) coincides with a decrease in blood flow velocities and an increase in vascular resistance in the canine ovary. The subsequent luteal recovery, as described after cessation of $\mathrm{PGF}_{2 \alpha}$ treatment (Romagnoli et al., 1993; Lange et al., 1997), was accompanied by a further increase in ovarian blood flow. Decreased ovarian perfusion as a result of $\mathrm{PGF}_{2 \alpha}$ treatment has also been observed in rabbits (Novy and Cook, 1973) and cows (Baumgartner et al., 1998). In canine pregnancy, patterns of intraovarian blood flow are very similar to those found in the non-pregnant luteal phase, as is the case for the progesterone concentrations of pregnant and non-pregnant bitches (Concannon et al., 1989).

Similar causal correlations between endocrine activity and blood supply have been demonstrated by investigations using Doppler ultrasonography of the dominant and the inactive ovary in women (Deutinger et al., 1989; Scholtes et al., 1989; Hata et al., 1990; Tan et al., 1996; Kurjak and Kupesic, 1997). Therefore, as in human reproduction, the results of the present study demonstrate the reliability of colour-coded and pulsed Doppler ultrasonography for detection and diagnosis of physiological and disturbed ovarian function, as shown by $\mathrm{PGF}_{2 \alpha}$-induced luteolysis.

With regard to individual variability of the Doppler parameter values, monitoring of the cyclic ovarian changes in bitches must be accompanied by other diagnostic procedures, such as vaginoscopy and cytology, as well as by analysis of the ovarian steroid hormones, particularly progesterone. For diagnostic purposes it is therefore essential to assess the progressive tendency of ovarian function for each bitch. As variations may also be attributed either to an inaccurate definition of the insonation angle between Doppler stream and alignment of the arterial segment or to a lack of exact anatomical correlates of the colour-coded pixel, repeated measurements should be performed at each examination. The significant differences found for certain values of the quantitative Doppler parameters between the left and right ovary highlight the necessity of an individual assessment of both gonads.

The knowledge of the physiological changes in ovarian perfusion in the oestrous cycle and in pregnant bitches, as shown in the present study, offers the basis for a better understanding of ovarian function and for the successful use of Doppler ultrasonography in the diagnosis of ovarian dysfunction and neoplasm in this species. However, further studies are needed to assess the relevance of this technique in canine reproductive medicine with regard to human gynaecology.

\section{References}

Andersen AC and Simpson ME (1973) Puberty - the first estrous cycle in pregnant and non-pregnant beagles. In The Ovary and Reproductive Cycle of the Dog (Beagle) pp 105-194 Eds AC Andersen and ME Simpson. Geron-X Inc., Los Altos, California 
Basset DL (1943) The changes in the vascular pattern of the ovary of the albino rat during the estrous cycle American Journal of Anatomy 73 251-291

Baumgartner U, Bollwein H, Maierl H, Böttcher P and Stolla R (1998 Colour Doppler sonography of the corpus luteum in cows during estrous cycle and after induction of luteolysis by $\mathrm{PGF}_{2 \alpha}$. Reproduction in Domestic Animals Supplement 524

Bourne TH, Campbell S, Steer CV, Whitehead MI and Collins WP (1989) Transvaginal color flow imaging: a possible new screening technique for ovarian cancer British Medical Journal 299 1367-1370

Bourne TH, Jurcovic D, Waterstone J, Campbell S and Collins WP (1991) Intrafollicular blood flow during human ovulation Ultrasound in Obstetrics and Gynecology 1 53-59

Bourne TH, Athanasiou S and Bauer B (1995) Ovulation and periovulatory follicle. In Transvaginal Colour Doppler pp 119-130 Eds H Bourne, E Jauniaux and D Jurkovic. Verlag Springer, Berlin, Heidelberg

Boyd JS, Renton RP, Harvey MJ, Nixon D, Eckersall PD and Ferguson JM (1993) Problems associated with ultrasonography of the canine ovary around the time of ovulation Journal of Reproduction and Fertility Supplement 47 101-105

Brännström $M$, Zackrisson $U$, Hagström HG, Josefsson B, Hellberg $P$, Granberg S, Collins WP and Bourne T (1998) Preovulatory changes of blood flow in the different regions of the human follicle Fertility and Sterility 69 435-442

Brown BW, Emery MJ and Mattner PE (1980) Ovarian arterial blood velocity measured with Doppler ultrasonic transducers in conscious ewes Journal of Reproduction and Fertility 58 295-300

Campbell S, Bourne TH, Waterstone J, Reynolds KM, Crayford TJB, Jurkovic D, Okokon EV and Collins WP (1993) Transvaginal color blood flow imaging of the periovulatory follicle Fertility and Sterility $\mathbf{6 0}$ 433-438

Cavender JL and Murdoch WJ (1988) Morphological studies of the microcirculatory system of periovulatory ovine follicle Biology of Reproduction 39 989-997

Collins WP, Jurcovic D and Bourne TH (1991) Ovarian morphology, endocrine function and intrafollicular blood flow during the periovulatory period Human Reproduction 6 319-324

Concannon PW (1993) Biology of gonadotropin secretion in adult and prepubertal female dogs Journal of Reproduction and Fertility Supplement 47 3-27

Concannon PW, Hansel W and Visek WJ (1975) The ovarian cycle of the bitch: plasma estrogen, $\mathrm{LH}$ and progesterone Biology of Reproduction $13112-121$

Concannon PW, Hansel W and McEntee K (1977) Changes in LH, progesterone and sexual behaviour with preovulatory luteinzation in the bitch Biology of Reproduction 17 604-613

Concannon PW, McCann JP and Temple M (1989) Biology and endocrinology of ovulation, pregnancy and parturition in the dog Journal of Reproduction and Fertility Supplement 39 3-25

Deeg KH, Woerle K and Schönau E (1990) Farbkodierte Dopplersonographie der Nierengefäße im Kindesalter Monatsschrift für Kinderheilkunde 138 256-267

Deutinger J, Reinthaller A and Bernaschek G (1989) Transvaginal pulsed Doppler measurement of blood flow velocity in the ovarian arteries during cycle stimulation and after follicle puncture Fertility and Sterility 51 466-470

Ellinwood WE, Nett TM and Niswender GD (1978) Ovarian vasculature: structure and function. In The Vertebrate Ovary pp 583-614 Ed. RE Jones. Plenum Press, New York, London

England GCW and Yeager AE (1993) Ultrasonographic appearance of the ovary and the uterus of the bitch during estrus, ovulation and early pregnancy Journal of Reproduction and Fertility Supplement 47 107-117

Espey LL (1976) The distribution of collagenous connective tissue in rat ovarian follicles Biology of Reproduction 14 502-506

Findlay JK (1986) Angiogenesis in reproductive tissues Journal of Endocrinology 111 357-366

Fleischer AC (1991) Ultrasound imaging 2000: assessment of uterineovarian blood flow with transvaginal color Doppler sonography; potential clinical applications in infertility Fertility and Sterility $\mathbf{5 5}$ 684-691

Ford SP and Chenault JR (1981) Blood flow in the corpus luteum-bearing ovary and ipsilateral uterine horn of cows during the oestrous cycle and early pregnancy Journal of Reproduction and Fertility 62 555-562

Goswamy RK (1993) Doppler sonographische Studien. In Funktionelle Sonographie in Gynäkologie und Reproduktionsmedizin pp 165-174 Eds U Deichert, V Duda and R Schlief. Verlag Springer, Berlin, Heidelberg

Günzel-Apel AR (1997) Läufigkeitskontrolle und Bestimmung des Bedeckungszeitpunktes. In Handlexikon der Tierärztlichen Praxis pp 500a-500h Ed. E Wiesner. Verlag Enke, Stuttgart

Günzel-Apel AR and Dieterich J (1996) Follikelreifung, Ovulation und Gelbkörperanbildung. In Atlas und Lehrbuch der Ultraschalldiagnostik bei Hund und Katze pp 248-257 Eds C Poulsen Nautrup and R Tobias. Schlütersche Verlagsanstalt, Hannover

Günzel-Apel AR, Brinckmann HG and Hoppen HO (1990) Dynamik der LH- und Testosteron-Sekretion bei Beagle-Rüden verschiedener Altersgruppen Reproduction of Domestic Animals 25 78-86

Hata K, Hata T, Senoh D, Makihara K, Aoki S, Takamiya O and Kitao M (1990) Change in ovarian arterial compliance during the human menstrual cycle by Doppler ultrasound British Journal of Obstetrics and Gynaecololy 97 163-166

Hayer PJ, Günzel-Apel AR, Lüerssen D and Hoppen HO (1993) Ultrasonographic monitoring of follicular development, ovulation and early luteal phase in the bitch Journal of Reproduction and Fertility Supplement 47 93-100

Höveler R (1991) Untersuchungen zur endokrinen Kontrolle der Ovarfunktion bei der graviden und ingraviden Hündin PhD Thesis, Faculty of Veterinary Medicine, University Giessen

Holst PA and Phemister RP (1974) Onset of diestrus in the beagle bitch definition and significance American Journal of Veterinary Research 35 401-406

Janson PO (1975) Effects of the luteinizing hormone on blood flow in the follicular rabbit ovary, as measured by radioactive microspheres Acta Endocrinologica 79 122-133

Jeffcoate JA and Lindsay FEF (1989) Ovulation detection and timing of insemination based on hormone concentrations, vaginal cytology and the endoscopic appearance of the vagina in domestic bitches Journal of Reproduction and Fertility Supplement 39 277-287

Klagsbrun M and D'Amore PA (1991) Regulators of angiogenesis Annual Review of Physiology 53 217-239

Kupesic S and Kurjak A (1993) Uterine and ovarian perfusion during the periovulatory period assessed by transvaginal color Doppler Fertility and Sterility 60 439-443

Kurjak A and Kupesic-Urec S (1991) Infertility. In Transvaginal Color Dopplerpp 33-38 Ed. A Kurjak. Parthenon, Lancs

Kurjak A and Kupesic S (1995) Ovarian senescence and its significance on uterine and ovarian perfusion Fertility and Sterility 64 532-537

Kurjak A and Kupesic S (1997) Transvaginale Dopplersonographie im Rahmen der Infertilitäts- und Tumordiagnostik. In Sonographische Diagnostik in Gynäkologie und Geburtshilfe, Volume 1, 2nd Edn pp 227-244 Ed. E Merz. Verlag Thieme Stuttgart, New York

Lange K, Günzel-Apel AR, Hoppen HO, Mischke R and Nolte I (1997) Effects of low doses of prostaglandin $F_{2 \alpha}$ during the early luteal phase before and after implantation in beagle bitches Journal of Reproduction and Fertility Supplement 51 251-257

Lee W and Novy MJ (1978) Effects of luteinizing hormone and Indomethacin on blood flow and steroidogenesis in the rabbit ovary Biology of Reproduction 17 799-807

Lindsay FEF (1983) The normal endoscopic appearance of the caudal reproductive tract of the cyclic and non-cyclic bitch: post uterine endoscopy Journal of Small Animal Practice 24 1-5

Locci M, Nazzaro G, Placido GDE, Nazzaro A and Renzo GCDI (1994) Angiogenesis: a new diagnostic aspect of obstetric and gynecologic echography Journal of Perinatal Medicine 21 453-473

Niswender GD, Moore RT, Akbar AM, Nett TM and Diekman MA (1975) Flow of blood to the ovaries of ewes throughout the estrous cycle Biology of Reproduction 13 381-388 
Novy MJ and Cook MJ (1973) Redistribution of blood flow by prostaglandin $\mathrm{F}_{2 \alpha}$ in the rabbit ovary American Journal of Obstetrics and Gynecology 117 381-385

Peters H and McNatty KP (1980) The vascular system and innervation. In The Ovary: A Correlation of Structure and Function in Mammals pp 31-33 Eds H Peters and KP McNatty. Granada Publishing, London, Toronto

Piascek BE and Huth JF (1971) Changes in ovarian venous blood flow following cannulation: effects of luteinizing hormone and antihistamine Proceedings Society for Experimental Biology and Medicine 138 1022-1024

Reynolds LP, Killilea SD and Redmer DA (1992) Angiogenesis in the female reproductive system FASEB Journal 6 886-892

Romagnoli SE, Camillo F, Cela M, Johnston SD, Grassi F, Ferdeghini M and Aria G (1993) Clinical use of prostaglandin $F_{2 \alpha}$ to induce early abortion in the mismated bitch: serum progesterone, treatment outcome and interval of subsequent estrus Journal of Reproduction and Fertility Supplement 47 425-431

Salpigtidou P (1998) Untersuchung der luteolytischen Wirkung von PGF $2 \alpha$ im ersten Drittel der Lutealphase der fehlgedeckten Hündin PhD Thesis, School of Veterinary Medicine, Hannover

Scholtes MC, Wladimiroff JW, Van Rijen HJM and Hop WCJ (1989) Uterine and ovarian flow velocity waveforms in the normal menstrual cycle: a transvaginal Doppler study Fertility and Sterility $\mathbf{5 2}$ 981-985

Schurz B, Schön HJ, Wenzl R, Eppel W, Huber J and Reinhold E (1993) Endovaginal Doppler flow measurements of the ovarian artery in patients with a normal menstrual cycle and with polycystic ovary syndrome during in vitro fertilization Journal of Clinical Ultrasound $\mathbf{2 1}$ $19-24$

Sieme H (1989) Bestimmung von Hämokoagulationsparametern im Blut zyklischer Stuten PhD Thesis, School of Veterinary Medicine Hannover

Sladevicius JT, O'Brian GD, Bains LM, Simpson J, Collins WP and Campbell S (1993) Blood flow velocity in the uterine and ovarian arteries during the menstrual cycle Ultrasound in Obstetrics and Gynecology 3 199-208

Sohn C (1995) Sonographische Durchblutungsdiagnostik in der Gynäkologie. In Ultraschall in Gynäkologie und Geburtshilfe pp 719-748 Eds C Sohn and W Holzgreve. Verlag Thieme, Stuttgart, New York

Sohn C, Stolz W and Bastert G (1993) Dopplersonographie in der Gynäkologie und Geburtshilfe. Verlag Thieme, Stuttgart, New York

Strigini FAL, Scida PAM, Parri C, Visconti A, Susini S and Genazzani AR (1995) Modifications in uterine and intraovarian artery impedance in cycles of treatment with exogenous gonadotropins: effect of luteal phase support Fertility and Sterility 64 76-80

Tan SL, Zaidi J, Campbell S, Doyle P and Collins W (1996) Blood flow changes in the ovarian and uterine arteries during the normal menstrual cycle American Journal of Obstetrics and Gynecology 175 625-631

Taylor KJW and Burns PN (1985) Duplex Doppler scanning in the pelvis and abdomen Ultrasound in Medical Biology 11 643-658

Tekay A and Jouppila P (1995) Blood flow in benign ovarian tumors and normal ovaries during the follicular phase Obstetrics and Gynecology $8655-59$

Tinkanen H, Kujansuu E and Laippala P (1995) The association between hormone levels and vascular resistance in uterine and ovarian arteries in spontaneous menstrual cycles - a Doppler ultrasound study Acta Obstetritia Gynecologica Scandinavia 74 297-301

Waberski D and Günzel-Apel AR (1990) Zyklusdiagnostik als Grundlage für fruchtbarkeitsfördernde und - hemmende Maßnahmen bei der Hündin Kleintierpraxis 35 573-580

Weiner Z, Thaler I, Levrom J, Lewit N and Itskovitz-Eldor J (1993) Assessment of ovarian and uterine blood flow by transvaginal color Doppler in ovarian-stimulated women: correlation with the number of follicles and steroid hormone levels Fertility and Sterility 59 743-749

Wildt DE, Panko B, Chakraborty PK and Seager SWJ (1979) Relationship of serum estrone, estradiol- $17 \beta$ and progesterone to $\mathrm{LH}$, sexual behaviour and time of ovulation in the bitch Biology of Reproduction 20 443-449

Wiltbank MC, Gallaher KP, Christensen AK, Brabec RK and Keyes PL (1990) Physiological and immunocytochemical evidence for a new concept of blood flow regulation in the corpus luteum Biology of Reproduction 42 139-149

Wurtman RJ (1964) An effect of luteinizing hormone on the fractional perfusion of the rat ovary Endocrinology 75 927-933

Zaidi J, Collins W, Campbell S, Pittrof R and Tan SL (1996) Blood flow changes in the intraovarian arteries during the periovulatory period: relationship to the time of day Ultrasound in Obsterics and Gynecology 7 135-140

Zalud I and Kurjak A (1990) The assessment of luteal blood flow in pregnant and non pregnant women by transvaginal color Doppler Journal of Perinatal Medicine 18 215-221

Received 10 January 2001.

First decision 29 March 2001

Accepted 16 May 2001. 